\title{
NUMERICAL ANALYSIS OF EMISSIONS FROM MARINE ENGINES USING ALTERNATIVE FUELS
}

\author{
Lamas, M.I., Assoc. Professor ${ }^{\mathrm{a}}$ \\ Rodríguez, C.G., Ph.D Student ${ }^{\mathrm{a}}$ \\ Telmo, J. Assoc. Professor ${ }^{\mathrm{b}}$ \\ Rodríguez, J.D., Assoc. Professor \\ a Escuela Politécnica Superior. Universidade da Coruña, Spain \\ b Escuela Politécnica Superior. Universidade de Santiago de Compostela, Spain
}

\begin{abstract}
The current restrictions on emissions from marine engines, particularly sulphur oxides $\left(\mathrm{SO}_{x}\right)$, nitrogen oxides $\left(\mathrm{NO}_{x}\right)$ and carbon dioxide $\left(\mathrm{CO}_{2}\right)$, are compelling the shipping industry to a change of tendency. In the recent years, many primary and secondary reduction techniques have been proposed and employed in marine engines. Nevertheless, the increasingly restrictive legislation makes it very difficult to continue developing efficient reduction procedures at competitive prices. According to this, the paper presents the possibility to employ alternative fuels. A numerical model was developed to analyze the combustion process and emissions using oil fuel, natural gas and hydrogen. A commercial marine engine was studied, the Wärtsilä $6 \mathrm{~L}$ 46. It was found, that hydrogen is the cleanest fuel regarding $\mathrm{CO}_{2}$, hydrocarbons (HC) and carbon monoxide (CO). Nevertheless, it is very expensive for marine applications. Natural gas is cheaper and cleaner than fuel oil regarding $\mathrm{CO}_{2}$ and $\mathrm{CO}$ emissions. Still, natural gas emits more $\mathrm{NO}_{x}$ and $\mathrm{HC}$ than oil fuel. $\mathrm{SO}_{x}$ depends basically on the sulphur content of each particular fuel.
\end{abstract}

Keywords: fuel; natural gas; hydrogen; marine engine; emissions

\section{INTRODUCTION}

Nowadays, environmental pollution is increasing at an alarming rate. In the marine field, ships are responsible for $15 \%$ of global $\mathrm{NO}_{\mathrm{x}}$ emissions, $6 \%$ of global $\mathrm{SO}_{\mathrm{x}}$ emissions and $2 \%$ of global $\mathrm{CO}_{2}$ emissions from fossil fuels, Skjølsvik et al. [1]. These important levels forced to limit emissions from ships by regional and international authorities such as Environmental Protection Agency, European Commission, International Maritime Organization, etc.. At the international level, the International Maritime Organization (IMO) is a United Nations agency that deals with maritime safety, security and pollution coming from ships. In 1973, the IMO adopted "MARPOL 73/78, The International Convention for the Prevention of Pollution from Ships", to minimize pollution coming from ships. MARPOL is the main international agreement addressing the issue of pollution coming from ships. Annex VI of the MARPOL, "Prevention of air pollution from ships" regulates $\mathrm{SO}_{x}, \mathrm{NO}_{\mathrm{x}}$ and, more recently, $\mathrm{CO}_{2}$. MARPOL Annex VI also regulates ozone depleting substances, volatile organic compounds from tankers, shipboard incineration and fuel oil characteristics.
Regarding $\mathrm{SO}_{\mathrm{x}}$, Annex VI of the MARPOL limits the sulphur content in fuels. From January 2012, the IMO requirements of maximum sulphur content in any fuel used onboard ships were reduced from $4.5 \%$ to $3.5 \%$. From January 2020, sulphur content should not exceed $0.5 \%$. The options for compliance with IMO new regulations include the use of low sulphur fuels/distillates, heavy fuel oil with a scrubber, natural gas, or other alternative fuels. Regarding $\mathrm{NO}_{\mathrm{x}}$, Annex VI of the MARPOL establishes a curve which indicates the maximum allowable $\mathrm{NO}_{\mathrm{x}}$ emission levels related to the engine speed, applicable to marine diesel engines built after 2000 (Tier I), 2011 (Tier II) and 2016 (Tier III). Regarding $\mathrm{CO}_{2}$, a new chapter has recently been added to MARPOL Annex VI, "Chapter 4, Regulations on energy efficiency for ships", to make the Energy Efficiency Design Index (EEDI) mandatory for new ships above 400 gross metric tons built after 1st January 2013 and the Ship Efficiency Management Plan (SEEMP) for all ships above 400 gross metric tons. The EEDI provides the grams of $\mathrm{CO}_{2}$ per ship's capacity-mile and is calculated by a formula based on the technical design 
parameters for a given ship. The SEEMP is an approach for shipping companies to manage ship and fleet efficiency performance over time.

Due to these legislative requirements, the rate of emissions is an important factor in the selection of marine engines. There are several strategies to reduce $\mathrm{NO}_{\mathrm{x}}$ emissions from marine engines such as geometry (Bigos and Puskar [2]), modification of injection parameters (Kontoulis et al., [3] and Pantiagonis et al. [4]), water addition (Lamas and Rodríguez [5]), EGR (Millo et al. [6]), SCR (Jayaran [7]), etc. Regarding $\mathrm{SO}_{x}$, an alternative to use low-sulphur fuels is to employ heavy fuel oil with scrubbers (Andreasen and Mayer [8]) or alternative fuels (Banawan et al. [9], Seddiek and Elgohary [10]). Regarding $\mathrm{CO}_{2}$, reduction measurements are so expensive that the only $\mathrm{CO}_{2}$ reduction techniques are to reduce speed and employ alternative fuels (Eide et al. [11]).

The aim of the present paper is to study the effect of alternative fuels in the emissions from marine engines. Three fuels were compared: fuel oil, natural gas and hydrogen. $\mathrm{CO}_{2}$, $\mathrm{HC}, \mathrm{CO}$ and $\mathrm{NO}_{\mathrm{x}}$ emissions were analyzed. $\mathrm{SO}_{\mathrm{x}}$ emissions were not analyzed because these depend on the sulphur content of each particular fuel. The engine analyzed was the Wärtsilä 6L 46 marine engine.

\section{ANALYZED ENGINE AND COMBUSTION PROCESS}

The Wärtsilä 6L 46 studied in the present work is a four-stroke, medium-speed marine diesel engine with six cylinders. Each cylinder has two intake and two exhaust valves. The numerical simulation of this engine and validation with experimental measurements were developed in previous works, Lamas et al. [12] and Lamas and Rodríguez [13]. The mesh employed in these works is indicated in Fig.1. A comparison between numerical and experimental in-cylinder pressure is indicted in Fig. 2. As can be seen, a good concordance was found. Numerical and experimental emissions were also satisfactory compared in Lamas and Rodríguez [12]. This study continues these previous works analyzing the influence of the fuel employed.
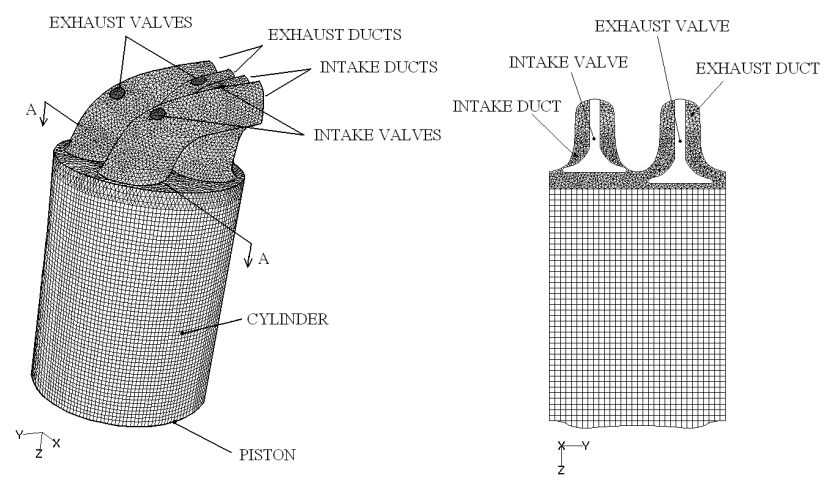

Fig 1. Computational mesh at bottom dead center position. (a) 3D view; (b) AA section

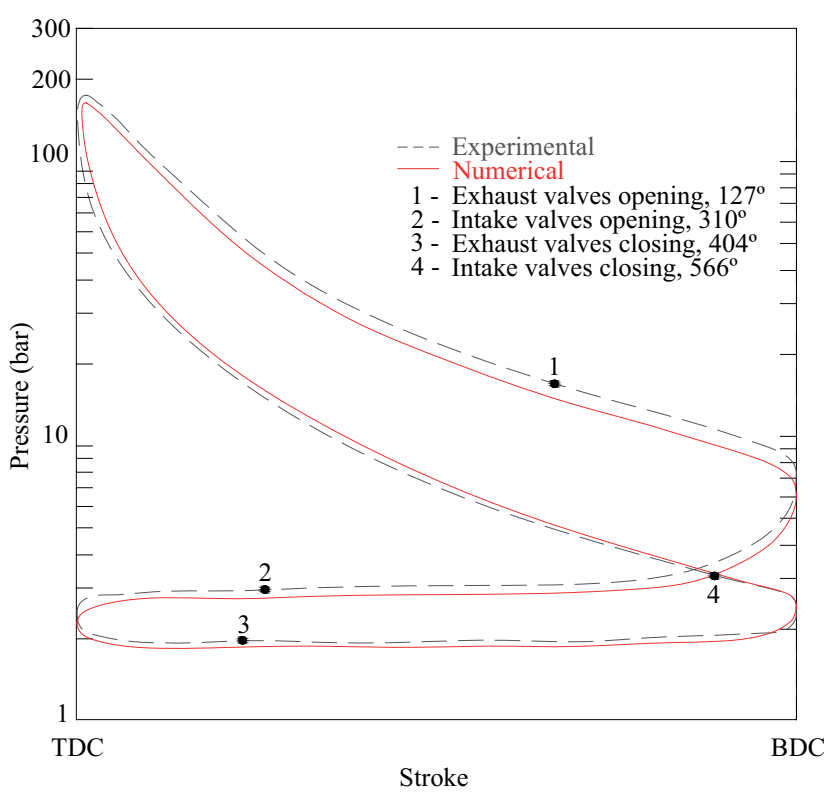

Fig 2. In-cylinder pressure obtained numerically and experimentally

Operating with fuel oil, this engine follows the diesel operating cycle. The injection system is indicated in Fig. 3. The fuel oil is introduced by a 10 holes injector in the form of a spray of liquid droplets. As the air contained in the cylinder is at high pressure and temperature, the fuel oil vaporizes and mixes with this air. After that, ignition takes place. Atomization, vaporization, fuel-air mixing and combustion continue until all the necessary fuel has passed through each process. In addition, mixing of the air remaining in the cylinder with burning and already burned gas continues throughout the combustion and expansion processes.

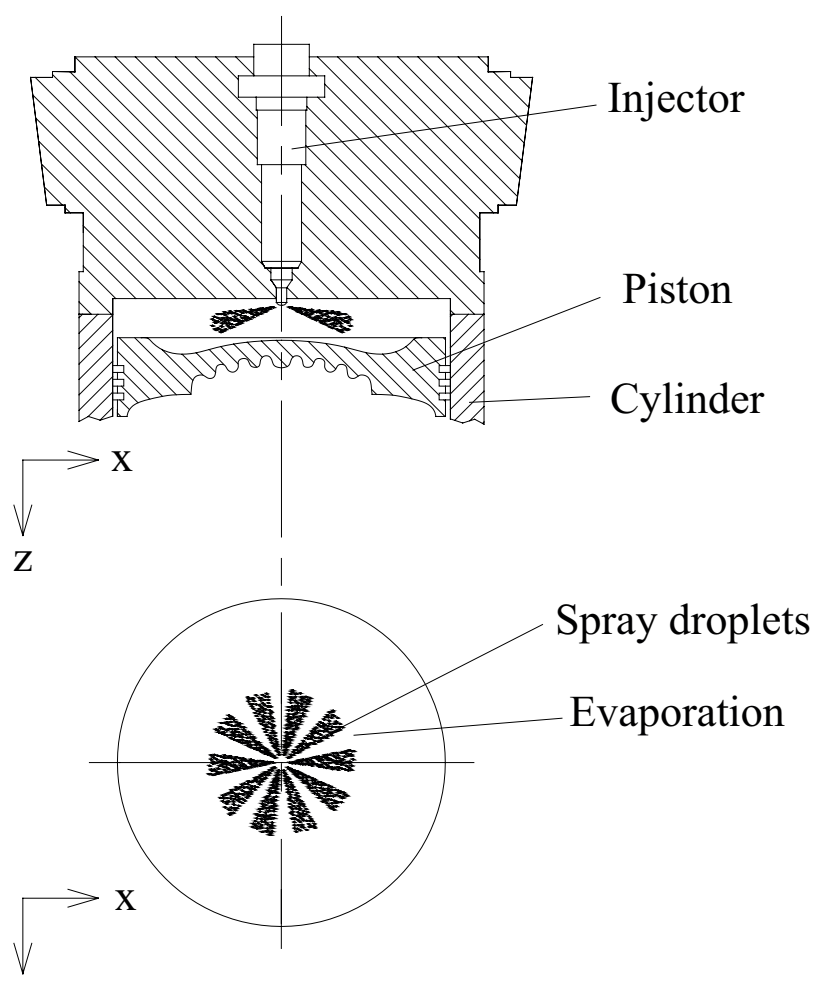

Fig. 3. Spray injection in the Wärtsilä $6 L 46$ 
Operating with gas, some marine engines employ the spark-ignited lean-burn Otto cycle. In this process the gas is mixed with air before the inlet valves and then ignited by a spark plug. The main disadvantage of this process is the risk of detonation because the auto-ignition of the mixture is difficult to control. In order to solve this problem, other marine engines are dual fuel powered and can operate in gas or fuel oil mode. Operating in gas mode, the gas is injected according to a diesel process at high pressure and is ignited by a pilot injection of diesel. These engines are more tolerant in terms of methane number than other gas engine concepts. Operating with hydrogen, both options $100 \%$ hydrogen and dual fuel are possible. Hydrogen engines also have a high risk of detonation.

\section{NUMERICAL PROCEDURE}

The engine described in the previous section was numerically simulated to analyze the emissions. Three fuels were employed, fuel oil, natural gas and hydrogen. Regarding natural gas and hydrogen, the dual fuel mode with pilot injection was simulated. A $1 \%$ amount of pilot fuel was initially employed, Wärtsilä [14], and the influence of this quantity was analyzed. The primary fuel, natural gas or hydrogen, controls the engine power output, while the pilot diesel fuel auto-ignites and creates ignition source for the surrounding gaseous fuel mixture to be burned.

The governing equations are indicated in the previous works, Lamas et al. [12] and Lamas and Rodríguez [13]. The conservation of mass, momentum and energy were solved. Since the flow inside the engine is turbulent, a turbulent model was used adding transport equations. Particularly, the k- $\varepsilon$ turbulence model was employed. In order to account for the combustion process, species conservation equations were solved.

\section{RESULTS}

Operating with fuel oil, the mass fraction of fuel is indicated in Fig. 4. The injection of fuel takes place from $-12^{\circ}$ to $-1^{\circ}$ crankshaft angles. Fig. 4 represents $-10^{\circ},-5^{\circ}$ and $0^{\circ}$ (top dead center). As can be seen, the mass fraction of fuel is high in the zone close to the fuel tip $\left(-10^{\circ}\right.$ and $\left.-5^{\circ}\right)$. After the injection of fuel has finished, the mass fraction of fuel is reduced progressively $\left(0^{\circ}\right)$.

A comparison of the fuel concentration using fuel oil, natural gas and hydrogen is indicated in Fig. 5. The $-10^{\circ}$ crankshaft angle is represented. As can be seen, hydrogen promotes the larger fuel concentration region. It releases a high amount of energy during combustion compared to both fuel oil and natural gas. Nevertheless, fuel oil has the smaller fuel concentration region, releasing a lower amount of energy. This behavior is also appreciated in Fig. 6, which indicates the in-cylinder pressure using fuel oil, natural gas and hydrogen. Hydrogen promotes higher pressures than fuel oil and natural gas while fuel oil promotes lower pressures.
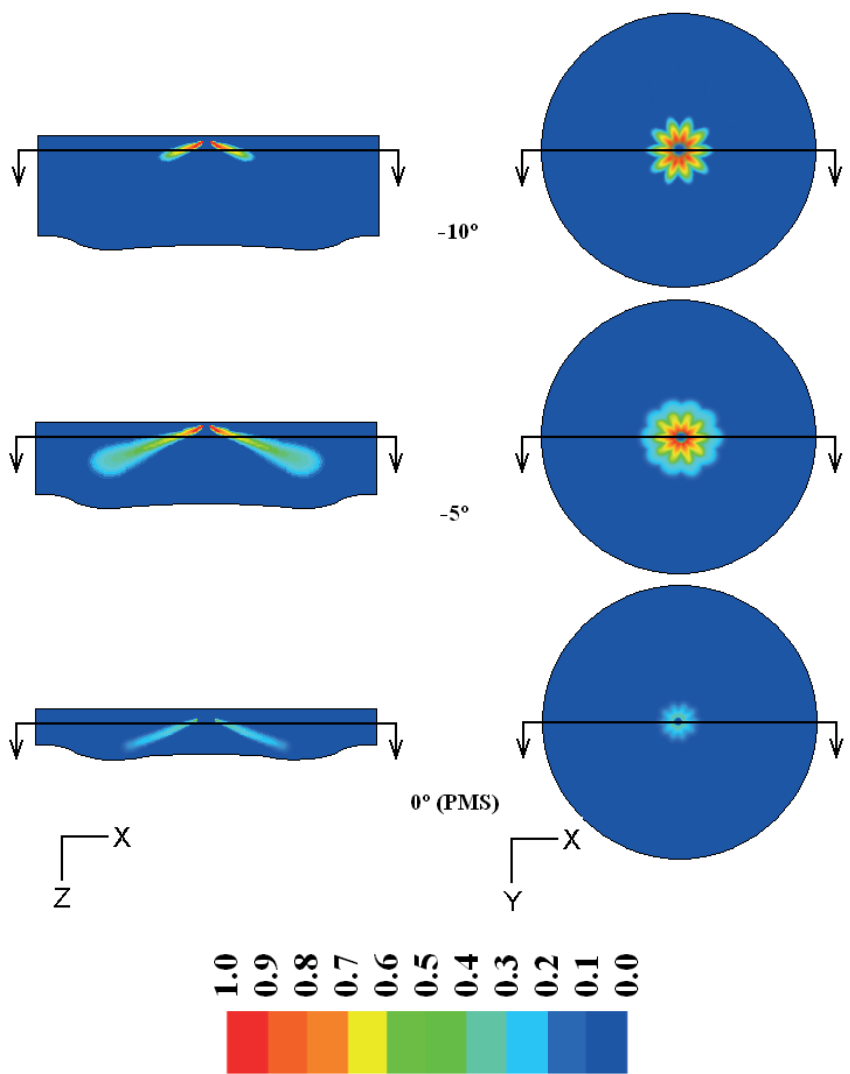

Fig 4. Mass fraction of fuel operating with fuel oil

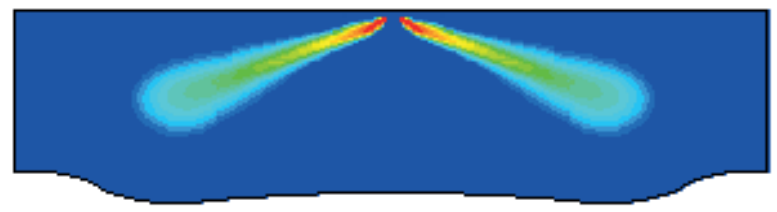

(a)

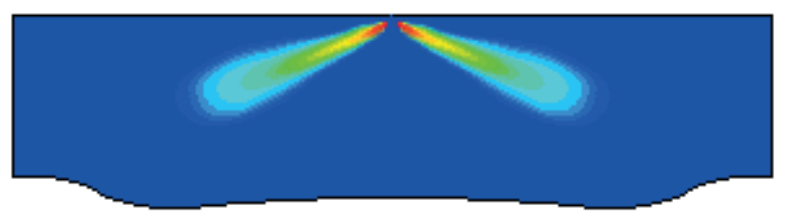

(b)

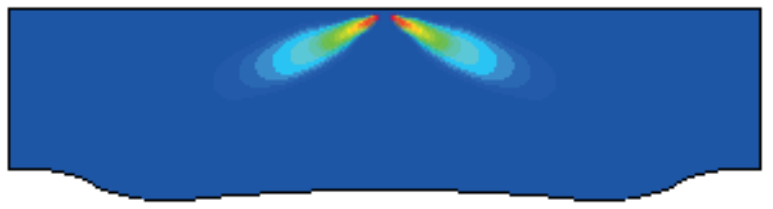

(c)

Fig. 5. Fuel concentration at $-10^{\circ}$; (a) fuel oil; (b) natural gas; (c) hydrogen 


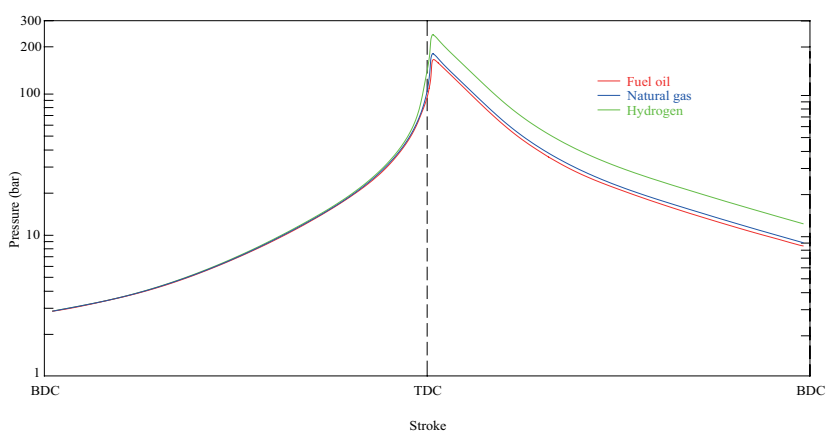

Fig. 6. In-cylinder pressure using fuel oil, natural gas and hydrogen

Regarding the temperature field, its characterization is very important to determine $\mathrm{NO}_{\mathrm{x}}$ formation since this pollutant is strongly dependent on the temperature. Higher temperatures promote higher $\mathrm{NO}_{\mathrm{x}}$ emissions. Table 1 indicates the maximum temperature, pressure and emissions in $\mathrm{g} / \mathrm{kW}$-h using the three fuels analyzed. As can be seen, hydrogen promotes the highest combustion temperature and thus high $\mathrm{NO}_{\mathrm{x}}$ emissions. Nevertheless, it is too clean regarding $\mathrm{CO}_{2}, \mathrm{CO}$ and $\mathrm{HC}$. It is worth to mention that $\mathrm{NOx}$ is relatively easy to reduce with the current technology due to the restrictive legislation imposed in the last years. This makes hydrogen a promising fuel if the price is reduced in the next years.

Regarding fuel oil and natural gas, $\mathrm{CO}_{2}$ and $\mathrm{CO}$ emissions are higher using fuel oil and $\mathrm{HC}$ emissions are lower. This is due to the $\mathrm{C} / \mathrm{H}$ proportion, which is higher for fuel oil than for natural gas. As natural gas has a lower $\mathrm{C} / \mathrm{H}$ proportion than fuel oil, $\mathrm{HC}$ emissions are higher and $\mathrm{CO}_{2}$ and $\mathrm{CO}$ emissions are lower.

Tab. 1. Emissions, maximum pressure and maximum temperature using fuel oil, natural gas and hydrogen

\begin{tabular}{c|cccccc}
\hline & $\begin{array}{c}\mathbf{C O}_{2} \\
(\mathbf{g} / \mathbf{k W}-\mathbf{h})\end{array}$ & $\begin{array}{c}\mathbf{C O} \\
(\mathrm{g} / \mathbf{k W}-\mathbf{h})\end{array}$ & $\begin{array}{c}\mathbf{N O}_{\mathbf{x}} \\
(\mathrm{g} / \mathbf{k} \text {-h) }\end{array}$ & $\begin{array}{c}\mathbf{H C} \\
(\mathbf{g} / \mathbf{k W}-\mathbf{h})\end{array}$ & $\begin{array}{c}\boldsymbol{P}_{\max } \\
(\mathbf{b a r})\end{array}$ & $\begin{array}{c}\boldsymbol{T}_{\max } \\
\left.{ }^{\circ} \mathbf{C}\right)\end{array}$ \\
\hline Fuel oil & 1490.4 & 4.08 & 11.8 & 4.66 & 182.3 & 2158.2 \\
Natural gas & 1221.2 & 2.41 & 14.7 & 7.61 & 191.3 & 2269.7 \\
Hydrogen & 7.45 & 0.008 & 17.2 & 0.011 & 233.4 & 2407.6 \\
\hline
\end{tabular}

The most important advantage of using hydrogen is the zero $\mathrm{CO}_{2}$ and $\mathrm{CO}$ emission levels. The small $\mathrm{CO}_{2}$ and $\mathrm{CO}$ amount is caused by the pilot injection to ignite the mixture. Fig. 7 indicates the emissions compared to the pilot percentage, from 1 to $20 \%$. As can be seen, increasing the pilot percentage reduces the $\mathrm{NO}_{\mathrm{x}}$ but increases $\mathrm{CO}_{2}$, $\mathrm{CO}$ and $\mathrm{HC}$ emissions. Regarding natural gas, emissions compared to the pilot percentage are indicated in Fig. 8. As expected, increasing the pilot percentage reduces $\mathrm{NO}_{x}$ and $\mathrm{HC}$ but increases $\mathrm{CO}_{2}$ and $\mathrm{CO}$.

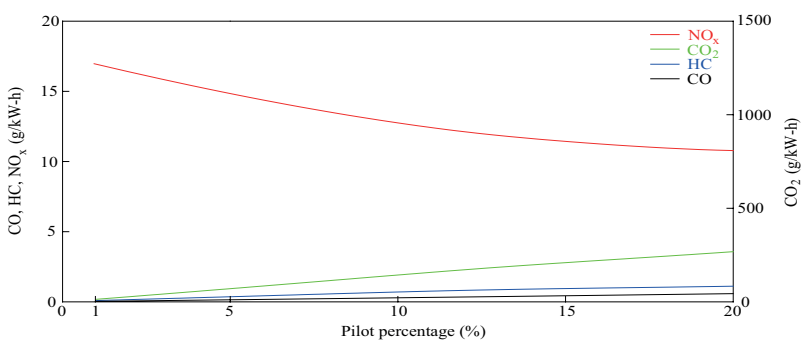

Fig. 7. Emissions against pilot percentage. Hydrogen.

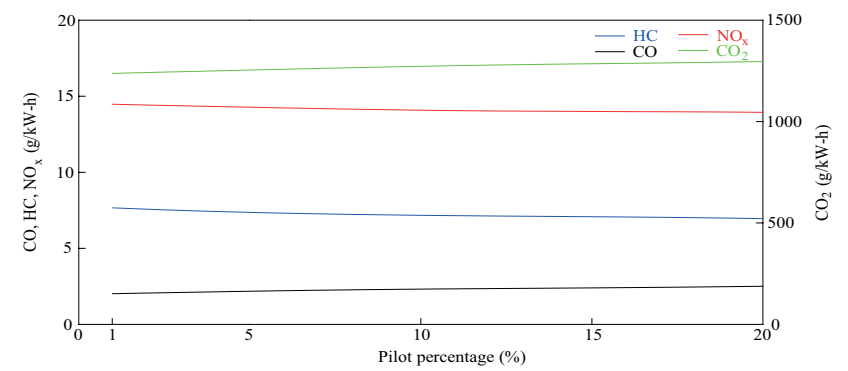

Fig. 8. Emissions against pilot percentage. Natural gas

\section{CONCLUSIONS}

Emissions from ships represent one of the main issues due to the negative impact on the environment. This paper employed a numerical model to compare three fuels in a commercial marine engine, the Wärtsilä 6L 46. Three fuels were compared: fuel oil, natural gas and hydrogen. $\mathrm{CO}_{2}, \mathrm{HC}$, $\mathrm{CO}$ and $\mathrm{NO}_{\mathrm{x}}$ emissions were analyzed. $\mathrm{SO}_{\mathrm{x}}$ emissions were not analyzed because these depend on the sulphur content of each particular fuel. It was found that, environmentally, hydrogen is the best option when $\mathrm{CO}_{2}, \mathrm{HC}$ and $\mathrm{CO}$ emissions are considered. Nevertheless, hydrogen is too expensive and emits more $\mathrm{NO}_{x}$ than fuel oil and natural gas. Nowadays, $\mathrm{NO}_{\mathrm{x}}$ reduction technologies have made considerable progress; still, the price constitutes an important problem to employ hydrogen in marine engines.

Natural gas is the best alternative fuel for marine applications due to its low cost, availability and adaptability for existing engines. The main disadvantage of natural gas is the risk of knocking. Natural gas can promote premature combustion and thus damaging vibrations. Fuel oil is more expensive than natural gas and emits more $\mathrm{CO} 2$, and $\mathrm{CO}$. Besides, due to the sulphur content in the fuel, fuel oil emits more SOx than natural gas and hydrogen.

\section{ACKNOWLEDGEMENTS}

The authors would like to express their gratitude to “Talleres Pineiro, S.L.", marine engines maintenance and repair shop. 


\section{REFERENCES}

1. Skjølsvik, K.O.; Andersen, A.B.; Corbett, J.J.; Skjelvik, J.M. Study on greenhouse gas emissions from ships. Final Report to the International Maritime Organization, MT Rep. Mtoo A23-038, MARINTEK, Trondheim, Norway, 2000

2. Bigos, P.; Puskar, M. Influence of cylinder shape and combustion space on engine output characteristic of two-stroke combustion engine. Zdvihací zařízení v teorii a praxi 3, 2008

3. Kontoulis, P.; Chryssakis, C; Kaitktsis, L. Analysis of combustion and emissions in a large two-stroke marine diesel engine using CFD and T- $\varphi$ mapping. 18th International Multidimensional Engine Modeling User's Group Meeting at the SAE Congress. Detroit, MI, 2008

4. Panagiotis, A.; Chryssakis, C.; Kaiktsis, L. Optimization of injection characteristics in a large marine diesel engine using evolutionary algorithms. SAE Paper 2009-01-1448, 2009

5. Lamas, M.I.; Rodriguez, C.G. Emissions from marine engines and NOx reduction methods, Journal of Maritime Research, volume 9(1), pp. 77-82, 2012

6. Millo, F.; Bernardi, M.G.; Delneri, D. Computational analysis of internal and external EGR strategies combined with Miller cycle concept for a two stage turbocharged medium speed marine diesel engine. SAE Paper 2011-011142,2011

7. Jayaran, V.; Nigam, A.; Welch, W.A.; Millar, J.W.; Cocker, I.I.: Effectiveness of emission control technologies for auxiliary engines on ocean-going vessels. Journal of the Air \& Waste Management Association, vol 61(1), pp 1421,2011

8. Andreasen, A.; Mayer, S. Use of seawater scrubbing for SO2 removal from marine engine exhaust gas. Energy and fuels, vol. 21, pp. 3274-3279, 2007

9. Banawan, A.A.; El-Gohary, M.M.; Sadek, I.S. Environmental and economical benefits of changing from marine diesel oil to natural gas fuel for sort-voyage highpower passenger ships. Engineering for the Maritime Environment, vol. 224, pp. 103-110, 2010

10. Seddiek, I.S.; Elgohary, M.M. Eco-friendly selection of ship emissions reduction strategies with emphasis on SOx and NOx emissions. International Journal of Naval Architecture and Ocean Engineering, vol. 6, pp. 737-748, 2014

11. Eide, M., Longva, T., Hoffmann, P., Endresen, Ø., and Dalsøren, S.: Future cost scenarios for reduction of ship
CO2 emissions. Maritime Policy \& Management., vol. 38, pp. 11-37, 2011

12. Lamas, M.I., Rodríguez, C.G. and Rebollido, J.M. Numerical model to study the valve overlap period in the Wärtsilä $6 \mathrm{~L} 46$ four-stroke marine engine. Polish Maritime Research, vol. 19(1), pp. 31-37, 2012

13. [13] Lamas, M.I. and Rodríguez, C.G. Numerical model to study the combustion process and emissions in the Wärtsilä 6L 46 four-stroke marine engine. Polish Maritime Research, vol. 20(2), pp. 61-66, 2013.

14. www.wartsila.com

\section{CONTACT WITH AUTHOR}

Lamas, M.I., isabellamas@udc.es 